\title{
Use of an Inner-city Well-baby Clinic
}

\author{
Cecilia E. Dawkins, Ph.D., R.N., \\ and Naomi E. Ervin, Ph.D., R.N.
}

\begin{abstract}
This prospective, longitudinal investigation examined factors that influenced the use of well-baby services among a low-income, minority, high-risk group. The health belief model was used as the theoretical framework. Data were collected from 44 primiparous, black mothers attending an urban maternal-child health care clinic by interviews at the first and sixth months after the birth of their infants. Analysis focused on the cues component of the model and explored the kinds of cues that influenced the mothers to bring their babies to the well-baby clinic. One important finding was that for mothers influenced by health information from radio or television, FYI commercials on television were most often reported.
\end{abstract}

Cecilia E. Dawkins, Ph.D., R.N. is Assistant Professor in Community Health Nursing at the University of Michigan School of Nursing, Ann Arbor, Michigan.

Naomi E. Ervin, Ph.D., R.N. is Assistant Professor in Public Health Nursing at the College of Nursing, University of Ilinois, Chicago, Illinois.

Appreciation is expressed to the Chicago Department of Health for their cooperation with this research.

Address correspondence to Cecilia E. Dawkins, Ph.D., R.N., University of Michigan School of Nursing, Community Health Nursing, 400 North Ingalls, Room 3187, Ann Arbor, MI 48109-0486. Telephone (313) $747-0341$.
As part of a study done to investigate mothers' health beliefs and their use of well-baby services, variables thought to result in their actual attendance to the clinic were explored. This paper examines factors that appear to have motivated 44 mothers to bring their babies to a well-child clinic for their one- and six-month visits.

Well-baby services include physical examination, immunizations, growth and development screening, counseling, and referral for appropriate special services. The benefits of these services include early detection of health and related problems (e.g., developmental, behavioral) and fostering of good health practices to promote optimum levels of wellness. Health personnel in well-child and community-oriented facilities devote much attention to the development of good health-maintenance practices among family members. Community health nurses in particular emphasize to new mothers the importance of regular well-baby clinic visits and obtaining immunizations. Nurses find, however, that clients, especially those from poor and minority groups, frequently do not make appointments or fail to keep those made. These kinds of client behaviors contribute to the frustration of community health nurses and the apparent ineffectiveness of nursing interventions. More effective models for nursing interventions could assist with the problem of inadequate health supervision of children.

A Health Resources Administration report indicated that nonwhites have lower immunization levels than whites for polio, measles, rubella, and diphtheria-typhoidpertussis (Rudov \& Santangelo, 1979). Also, data from the 1982 National Access Survey supported by the Robert Wood Johnson Foundation (1983) revealed that while poor Americans have more physician visits per year than the nonpoor ( 5.9 versus 4.7 ), this is partially because of their poorer health status. The survey further stated: 
On many indicators of access to care, black Americans are much worse off than national averages. Black-white differentials are even sharper. Black families were much less likely than white families to obtain care when they needed it. ... They rate their own health status less favorably . . . (p. 7)

These types of factors served as rationale to focus this study on a low-income, black, high-risk group.

\section{CONCEPTUAL FRAMEWORK}

The health belief model (HBM) was the conceptual framework for the study. Research has examined sociopsychologic factors as an approach to understanding health-seeking behaviors. The HBM is one such conceptualization that seeks to explain preventive health behavior. The model posits that whether or not an individual will take a preventive health action is dependent on several variables: perceived susceptibility and perceived severity; perceived benefits of the action; perceived barriers to taking an action; modifying factors of a demographic and sociopsychologic nature; and cues to action. The HBM posits that for persons to take a recommended preventive health action, they would (1) perceive themselves to be vulnerable to a particular health condition (perceived susceptibility); (2) perceive the condition to have serious consequences (perceived severity); (3) perceive that the benefits of taking the action outweigh costs or barriers (perceived benefits minus perceived barriers); and (4) have received a cue or cues to take the action. Demographic variables such as age, sex, race, and ethnicity, and sociopsychologic variables such as social status and peer and reference groups can also influence whether or not the preventive health action is taken (Becker, Haefner, Kasl, Kirscht, Maiman, \& Rosenstock, 1977).

In predicting the preventive health behavior, the cues component is considered essential, as this cue triggers the individual to perform the health action. Yet the cues component is the least studied and least understood part of the HBM. After over three decades of the model's existence, there continues to be a paucity of research involving this area and a definite need to understand what finally stimulates the client to use preventive health services (Hochbaum, 1983). The cues component was explored by investigating the types of cues that influenced mothers to bring their infants to a well-baby clinic.

\section{METHODS \\ Sample and Site}

The sample for the overall study was composed of 61 subjects who attended a maternal and child health care clinic from November 1981 through June 1982. This paper reports on the 44 women who attended the clinic during that time for the well-child health care services at the first-month and six-month visits. The median age for these black mothers was 18 years. The range in age was from 14 to 25 years, with approximately threefourths of them less than 20 years old. The majority (98.2\%) had never married and were relatives of a female household head with a reported median annual household income of $\$ 5000$. While most of the mothers were unemployed $(96.6 \%)$, many $(58.9 \%)$ were enrolled in school.

The clinic for the study sample is operated by the Chicago Department of Health and located in a predominantly black, inner-city community with a high percentage of young, low-income residents. The clinic provides maternal and child health care services and family planning.

\section{Procedure}

The research was a longitudinal, prospective study with three interviews administered to each subject: at one prenatal visit, at the baby's first well-baby visit, and at the baby's sixth-month well-baby visit. As previously stated, this report examines aspects of the baby's firstand sixth-month visits.

The subjects were eligible to be in the study as a result of a record audit with the following criteria: firsttime mother; no chronic disease such as hypertension or diabetes; and normal progress in the pregnancy. The mother-baby dyad was eliminated from the study if (1) the mother had had multiple births; (2) the mother or child became separated, seriously ill, or died during the study period; or (3) the mother and child changed their residence to outside the clinic's service area.

The interviews were conducted in the clinic by three experienced community health nurses who were not employed by the clinic. To maximize cooperation and subject comfort, an attempt was made to match the interviewers with the respondents in terms of race and sex. Procedures were followed that provide for the protection of human subjects. Approximately 30 minutes were required to complete each interview.

\section{The Instrument}

The instrument was developed by the investigators and was based on (1) a review of the literature of previous studies using the health belief model; (2) previous reports of health use surveys; (3) the experiences of the investigators with health use research; and (4) a pretest conducted at the clinic site. The instrument consisted of structured interviews that consisted largely of closed precoded questions; however, several open-ended questions were included in the cues section of the interviews. This was necessary to probe the respondents for the factors that they felt influenced their attendance. 


\section{RESULTS}

According to the health belief model, cues trigger the person to perform the recommended preventive action. In this study, the recommended preventive behavior was visits for well-child health services. Table 1 presents cues that influenced the mothers to make the initial and the sixth-month visits. Over one-half of the mothers remembered a talk with a health professional about bringing their babies in for check-ups and shots. There was no statistically significant difference in their responses at the two visits.

Table 1 shows that almost two-thirds $(65 \%)$ of the mothers remembered a talk with a friend or relative prior to the first visit about bringing the baby into the clinic for a check-up and shots. Only one-third remembered such a talk prior to the sixth-month visit. This difference in responses was statistically significant $\left(\chi^{2}\right.$ $=5.69 ; P<0.02$ ).

There was no statistically significant difference in responses between the visits of mothers who remembered reading an advertisement or story about check-ups and/ or baby shots prior to bringing their babies to the clinic
( $43 \%$ and $36 \%$, respectively). While 41 percent of the mothers remembered information on the radio or television about well-child check-ups and shots prior to the first-month visit, 64 percent remembered similar information prior to the sixth-month visit. Although this was not statistically significant $\left(\chi^{2}=2.32 ; P<0.10\right)$, it does point to the importance of radio and television media that may prove significant with a larger sample.

It is interesting to note that of the 17 mothers (41\%) who remembered information prior to the first visit from radio or television, 14 responded in the open-ended statement that the information was seen on television in a short segment called FYI with host Hal Linden. Equally noteworthy, prior to their sixth-month visits, 8 of the 16 mothers who remembered information from the media also reported that it was the FYI television segment broadcast between soap operas. Wittenberg (1983) also reported that women in a market survey for the "healthy mothers, healthy babies" campaign found the FYI programs to be valuable.

Generally, the mothers reported that the talk with a health professional, friend, and/or relative had influenced them to bring their babies to the clinic for the

TABLE 1. Cues at the First- and Sixth-month Visits

\begin{tabular}{|c|c|c|c|c|c|c|c|c|c|}
\hline \multirow[t]{2}{*}{ Cue } & \multicolumn{2}{|c|}{$\begin{array}{l}\text { 1st-month } \\
\text { Visit } \\
\% \text { (No.) }\end{array}$} & \multicolumn{2}{|c|}{$\begin{array}{l}\text { 6th-month } \\
\text { Visit } \\
\text { \% (No.) }\end{array}$} & & \multicolumn{2}{|c|}{$\begin{array}{l}\text { 1st-month } \\
\text { Visit } \\
\% \text { (No.) }\end{array}$} & \multicolumn{2}{|c|}{$\begin{array}{l}\text { 6th-month } \\
\text { Visit } \\
\% \text { (No.) }\end{array}$} \\
\hline & & $44^{\circ}$ & $N=$ & $=33^{\circ}$ & & $N=$ & $=44$ & $N=$ & $=33$ \\
\hline $\begin{array}{l}\text { Remembered a talk } \\
\text { with health } \\
\text { professional about } \\
\text { bringing baby for } \\
\text { check-up and shots }\end{array}$ & $\begin{array}{l}\text { Yes } \\
\text { No } \\
\text { Total }\end{array}$ & $\begin{array}{r}56(24) \\
44(19) \\
100(43)\end{array}$ & $\begin{array}{l}\text { Yes } \\
\text { No } \\
\text { Total }\end{array}$ & $\begin{array}{l}52(13) \\
48(12) \\
100(25)\end{array}$ & $\begin{array}{l}\text { The talk influenced you } \\
\text { to bring in baby } \\
\text { today. }\end{array}$ & $\begin{array}{l}\text { Yes } \\
\text { No } \\
\text { Total } 1\end{array}$ & $\begin{array}{r}67(16) \\
33(8) \\
100(24)\end{array}$ & $\begin{array}{l}\text { Yes } \\
\text { No } \\
\text { Total i }\end{array}$ & $\begin{array}{r}92(12) \\
8(1) \\
100(13)\end{array}$ \\
\hline $\begin{array}{l}\text { Remembered a talk } \\
\text { with friend or relative } \\
\text { about bringing baby } \\
\text { for check-up and } \\
\text { shots }\end{array}$ & $\begin{array}{l}\text { Yes } \\
\text { No } \\
\text { Total }\end{array}$ & $\begin{array}{r}65(28) \\
35(15) \\
100(43)\end{array}$ & $\begin{array}{l}\text { Yes } \\
\text { No } \\
\text { Total }\end{array}$ & $\begin{array}{l}32(8) \\
68(17) \\
100(25)\end{array}$ & $\begin{array}{l}\text { The talk influenced you } \\
\text { to bring in baby } \\
\text { today. }\end{array}$ & $\begin{array}{l}\text { Missing } \\
\text { Yes } \\
\text { No } \\
\text { Total }\end{array}$ & $\begin{array}{l}11(3) \\
75(21) \\
14(4) \\
100(28)\end{array}$ & $\begin{array}{l}\text { Yes } \\
\text { No } \\
\text { Total i }\end{array}$ & $\begin{array}{r}88(7) \\
12(1) \\
100(8)\end{array}$ \\
\hline $\begin{array}{l}\text { Remembered reading } \\
\text { an advertisement or } \\
\text { story about check-ups } \\
\text { and/or shots for well } \\
\text { babies }\end{array}$ & $\begin{array}{l}\text { Yes } \\
\text { No } \\
\text { Total }\end{array}$ & $\begin{array}{l}43(18) \\
57(24) \\
100(42)\end{array}$ & $\begin{array}{l}\text { Yes } \\
\text { No } \\
\text { Total }\end{array}$ & $\begin{array}{l}36(9) \\
64(16) \\
100(25)\end{array}$ & $\begin{array}{l}\text { What you read } \\
\text { influenced you to } \\
\text { bring in baby today. }\end{array}$ & $\begin{array}{l}\text { Missing } \\
\text { Yes } \\
\text { No } \\
\text { Total }\end{array}$ & $\begin{array}{l}5(1) \\
72(13) \\
22(4) \\
99(18)\end{array}$ & $\begin{array}{l}\text { Missing } \\
\text { Yes } \\
\text { No } \\
\text { Total }\end{array}$ & $\begin{array}{l}811(1) \\
77(7) \\
11(1) \\
99(9)\end{array}$ \\
\hline $\begin{array}{l}\text { Remembered anything } \\
\text { on radio or television } \\
\text { about check-ups and/ } \\
\text { or shots for well } \\
\text { babies }\end{array}$ & $\begin{array}{l}\text { Yes } \\
\text { No } \\
\text { Total }\end{array}$ & $\begin{array}{l}41(17) \\
58(24) \\
99(41)\end{array}$ & $\begin{array}{l}\text { Yes } \\
\text { No } \\
\text { Total }\end{array}$ & $\begin{array}{r}64(16) \\
36(9) \\
100(25)\end{array}$ & $\begin{array}{l}\text { What you heard on } \\
\text { radio or television } \\
\text { influenced you to } \\
\text { bring baby in today. }\end{array}$ & $\begin{array}{l}\text { Yes } \\
\text { No } \\
\text { Total }\end{array}$ & $\begin{array}{r}41(7) \\
59(10) \\
100(17)\end{array}$ & $\begin{array}{l}\text { Missing } \\
\text { Yes } \\
\text { No } \\
\text { Total }\end{array}$ & $\begin{array}{r}6(1) \\
68(11) \\
25(4) \\
99(16)\end{array}$ \\
\hline
\end{tabular}

One to three observations are missing for each statement. Percentages may not total 100 percent because of rounding.

'Between the first-month and the sixth-month visit, 11 subjects were unable to be located for interview; hence $N=44$ and $N=33$ at the first- and sixth-month visits, respectively. Eight subjects did not make the sixth-month visit and were not asked questions regarding cues; therefore, the total of 25 respondents. 
first- and sixth-month visits. No statistical tests were performed for this and the others in columns 5 and 6 of Table 1 to see if there was a statistically significant difference in responses at the two visits. This was because of the small number of responses in those categories. Therefore we can only point to a direction and provide cautious observations with limited generalizability external validity. This direction seems to be that the mothers who remembered a discussion with a health professional or friend were influenced to make the visits. Generally, this was the case for those who remembered a source from the media.

Table 2 presents the numbers of sources of information that were remembered by the respondents that were reported to influence their attendance at the first- and sixth-month visits. A definite pattern cannot be documented because of the small numbers in the categories. There appears to be a trend, however, whereby the higher the number of sources of information, the more likely the respondents reported that the source(s) influenced their clinic attendance. For example, 12 respondents reported recalling one source of information prior to the first-month visit. Six reported that it influenced their attendance and six stated that it did not. When eight respondents remembered three sources of information prior to their first-month visit, one or more of the sources influenced their attendance. This trend held for the attendance at the sixth-month visit.

\section{IMPLICATIONS}

The results of this study point to the need to reinforce teaching through various media and at various times for young pregnant women and new mothers. The same message given clearly, concisely, and at appropriate times was effective in influencing these new mothers to take their infants for well-baby services. Although caution is required in drawing implications from a study with a small sample size, some suggestions can be made for nursing practice at the agency, group, and individual level.

\section{Agency Level}

One of the areas of implications for agencies is in marketing strategies for well-baby services. Targeting populations with the lowest rates of use of services to be exposed to appropriately prepared advertisements could contribute to increased use of services. This strategy would require that funds be allocated for marketing activities and materials. The limited data in this study point to the need for several methods for emphasizing the importance of well-child services. An agency should have some ideas about which types of media are best noted and received by the target population. For example, in this study, 14 of 17 subjects who remembered a medium as a source of information prior to their first visit reported having seen something on a television commercial about infants' health. Because this was aired between programs watched by many of the respondents, this particular segment of the study population was likely to see the commercial. One market survey (Wittenberg, 1983) also found that urban black women obtained health information from soap operas and other television programs.

In addition, locations for marketing well-child services could include supermarkets, churches, and neighborhood clubs. As many of these have been successfully used throughout the years, one can assume continued need for several locations and types of media for advertising available well-child services.

\section{Group Level}

Working with groups is an important aspect of community health nursing. Groups may consist of individuals with similar characteristics and health needs, such as new parents or unwed adolescents, or include whole

TABLE 2. Numbers of Sources of Information that Influenced Attendance at the Well-child Clinic

\begin{tabular}{|c|c|c|c|c|c|c|c|}
\hline \multicolumn{4}{|c|}{ First-month Visit } & \multicolumn{4}{|c|}{ Sixth-month Visit } \\
\hline \multirow{2}{*}{$\begin{array}{l}\text { No. of } \\
\text { Sources }\end{array}$} & \multicolumn{2}{|c|}{ No. Influencing } & \multirow{2}{*}{$\begin{array}{l}\text { Totals } \\
\text { No. } 1 \%\end{array}$} & \multirow{2}{*}{$\begin{array}{l}\text { No. of } \\
\text { Sources }\end{array}$} & \multicolumn{2}{|c|}{ No. Influencing } & \multirow{2}{*}{$\begin{array}{l}\text { Totals } \\
\text { No. } 1 \%\end{array}$} \\
\hline & 0 & 1 or More & & & $\mathbf{0}$ & 1 or More & \\
\hline 1 & 6 & 6 & $12 / 28$ & 1 & 4 & 5 & $9 / 39$ \\
\hline 2 & 5 & 13 & $18 / 43$ & 2 & 1 & 6 & $7 / 30$ \\
\hline 3 & 0 & 8 & $8 / 19$ & 3 & 0 & 3 & $3 / 13$ \\
\hline 4 & 0 & 4 & $\frac{4 / 10}{42 / 100}$ & 4 & 0 & 4 & $\frac{4 / 17}{23 / 100}$ \\
\hline
\end{tabular}

Forty-four subjects were interviewed for the first-month visit, with data missing on two. At the sixth-month visit, 23 subjects were interviewed for the cues section. An additional eight did not make the sixth-month visit, data are missing on two, and the remainder could not be located for interview. 
families. All offer opportunities for using strategies that may enhance the use of well-baby services.

In this study, 75 percent of 28 subjects were influenced by a talk with a friend or relative to take their children for well-baby services. This could mean that education must not be limited only to parents. Research has indicated that behavior can be influenced by interaction with others, and this study indicated that at least friends and relatives had some influence on the mothers to attend the well-baby clinic.

\section{Individual Level}

The implications of this study at the individual level of practice are closely related to those at the group level. For the reasons cited above, it appears that community health nurses should systematically include family members, friends, and significant others in teaching new mothers. Not only can the other individuals assist with infant care, they can reinforce the nurse's teaching about the importance of well-baby services.

In the final analysis, the information from investigations such as this can provide the basis for health education and other strategies, such as marketing, to increase the systematic use of well-baby services for high-risk groups. Another investigation with a larger sample size is being conducted by the authors to gain further insight into what factors influence the nonusers as well as the users of such services.

\section{REFERENCES}

Becker, M. H., Haefner, D. P., Kasl, S. V., Kirscht, J. P., Maiman, L. A., \& Rosenstock, I. M. (1977). Selected psychosocial models and correlates of individual healthrelated behaviors. Medical Care, 15, 27-46.

Hochbaum, G. (1983). The health belief model after three decades. Paper presented at the annual meeting of the American Public Health Association, Dallas, Texas.

Robert Wood Johnson Foundation (1983). Updated report on access to health care for the American people, special report. Princeton, NJ: Author.

Rudov, M. H., \& Santangelo, N. (1979). Health status of minorities and low-income groups. Washington, DC: Government Printing Office, DHEW Publication No. (HRA) 79-627.

Wittenberg, C. K. (1983). Summary of market research for "healthy mothers, healthy babies" campaign. Public Health Reports, 98(4), 356-359. 